\title{
Memes y reacciones ciudadanas en las campañas electorales de Perú (2016) y Bolivia (2019)
}

\author{
Memes and citizen reactions in political campaigns \\ in Peru (2016) and Bolivia (2019)
}

\section{Carlos Gonzales-García}

Universidad Nacional Mayor de San Marcos, Lima, Perú

carlos.gonzales1dunmsm.edu.pe

https://orcid.org/0000-0001-9408-4329

\section{Janeth Villegas-Arteaga}

Universidad Nacional Mayor de San Marcos, Lima-Perú jvillegasaAunmsm.edu.pe https://orcid.org/0000-0002-5045-2561

\section{Resumen}

Esta investigación se enfoca en el análisis de los memes utilizados en las campañas electorales de Perú (2016) y Bolivia (2019) en Facebook con el objetivo de identificar sus características y las reacciones más notables. Al respecto, analizamos un total de 80 memes que circularon en el marco de dichas campañas y aplicamos una encuesta a 300 ciudadanos entre 18 y 45 años de ambos países. De acuerdo a los resultados, las categorías estudiadas resaltan el prestigio/desprestigio de los candidatos, la calidad política desde el punto de vista de figuras y partidos; la pobreza de los mensajes de estos aspirantes; la identificación del candidato con la cultura de su país, y su capacidad intelectual. En cuanto a lo obtenido por parte de las encuestas, el segmento más joven y con menor escolaridad, en ambos países, es el que otorga mayor importancia a los memes como estrategia política.

Palabras clave: memes políticos; campañas electorales; comunicación política; Perú; Bolivia.

\begin{abstract}
This research analyses memes in the context of electoral campaigns of Peru (2016) and Bolivia (2019) on Facebook in order to identify their main features and the most remarkable reactions. Then, we analysed a purposeful sample of 80 memes shared in the course of the aforementioned campaigns and a survey was applied to 300 citizens between 18 and 45 years old in both countries. The study shows that the main features identified highlight the candidates' prestige/discredit, the political quality from the point of view of main players and political parties, the triviality of nominees' messages, the self-identification of nominees with his or her country's culture, and his or her brainpower. Finally, according to the surveys, the youngest and least educated populations in both countries are the ones valuing the greatest relevance to memes as a political strategy.
\end{abstract}

Keywords: political memes; electoral campaigns; political communication; Perú; Bolivia 


\section{Introducción}

América Latina es una región que atraviesa constantes cambios, a menudo en direcciones opuestas y contradictorias. Desde la década de 1990, muchos países de la región han experimentado el colapso de sus sistemas de partidos a la par de hiperinflación y graves recesiones económicas. En la zona andina, Perú y Bolivia fueron algunas de las naciones donde surgió el autoritarismo competitivo, entendido como el que, si bien las instituciones democráticas existen, el abuso del poder sesga el campo de juego en contra de los opositores (Levitsky \& Loxton, 2013). En la década de 2000, la región vio el resurgimiento y el ascenso al poder de la izquierda, para que luego, en el período siguiente, excepto por unos pocos países, se dé una tendencia inversa. A raíz de estos acontecimientos, algunos movimientos de la sociedad civil han ido participando activamente haciendo posible la política de la protesta. En ese contexto, advertimos que los medios digitales se han constituido en soportes que proporcionan herramientas para el debate político interpersonal y los mensajes cívicos en línea, contribuyendo a una mayor participación ciudadana (Shah et al., 2005).

En Perú y Bolivia, rivalizando con el poder movilizador de los modos tradicionales de información y expresión, la participación ciudadana se ha ido dando a través de redes sociales, principalmente a través de Facebook, la más preferida (94\%) por peruanos y bolivianos (Ipsos, 2020; Ibáñez, 2021). En esta plataforma, los memes son uno de los instrumentos virtuales que forjan la opinión de los ciudadanos (Tejada, 2020).

Hay una abundante literatura sobre la palabra meme desde que el biólogo evolutivo Dawkins la acuñara en su libro The Selfish Gene en 1976 (Lumsden \& Wilson, 1981; Durham, 1991; Bull, Holland \& Blackmore, 2000; Rushkoff, 2010; Leal-Toledo, 2013). Desde entonces y hasta ahora, el concepto se ha convertido en una de las "nuevas ciencias" más exitosas de la inteligencia computacional, extendiendo su influencia a los campos de la antropología, la biología, la cognición, la psicología, la sociología y la sociobiología (Ong, Lim \& Chen, 2010).

En internet, la historia de los memes se inició con gifs animados. Éstos comenzaron a compartirse a través de correos electrónicos, dando paso a men- sajes informales para entretener. Entre 2000 y 2004, aparecieron los primeros memes acompañados por textos creativos en foros y páginas como Somethingawful.com, Milkandcookies.org y Fark.org (Knobel \& Lankshear, 2007). La irrupción y posterior masificación relativa de los teléfonos móviles inteligentes propició el uso de textos más breves. Estas nuevas formas de comunicación comenzaron a divulgar imágenes, videos, canciones, frases o bromas que eran seleccionadas, modificadas y transmitidas masivamente de cuenta a cuenta a través de redes sociales digitales (García, 2014) o por distintos entornos virtuales (Pérez, Aguilar \& Guillermo, 2014). Este fenómeno dio lugar a que los memes se convirtieran, paulatinamente, en una estrategia importante en el mundo de las comunicaciones y en las plataformas digitales, espacios donde adoptan el carácter de las personas que los crean y consumen (Rathore, 2019).

Entendemos el meme como una herramienta de comunicación que representa una cultura replicable y transmisible por imitación. Bajo esa perspectiva, esta investigación analiza la participación política en línea durante los periodos electorales presidenciales en dos países andinos. Nos centramos especialmente en los contenidos de los memes políticos y las reacciones que generaron en la cultura digital en cuanto a su uso según rango de edad y escolaridad, fenómenos poco estudiados en el mundo académico (Shomova, 2019). Particularmente, examinamos el uso de estas unidades de información en las elecciones de Perú (2016) y Bolivia (2019), no sólo porque fueron sus últimos procesos electorales de la segunda década del siglo XXI, sino porque se produjeron en dos contextos diferentes en cuanto a su política democrática y económica. Mientras en Bolivia el gobierno del entonces presidente Evo Morales solidificaba y extendía su poder desde 2005 bajo un régimen económico socialista; en el caso de Perú, en tanto, bajo la influencia de un modelo político y económico neoliberal, enfrentaba a convocatoria a un cuarto periodo democrático desde la caída del régimen de Fujimori en 2001.

\section{Marco teórico}

Los memes son parte importante de la estrategia comunicativa de toda campaña electoral porque permiten "concretar formas de pensar, comporta- 
mientos y acciones tanto del partido político que los emite como de la comunidad que los valora" (Piñero-Otero \& Martínez-Rolán, 2016). A través de Internet, los memes se convierten en fenómenos virales que comunican "un suceso, material o idea [...] que es seleccionada, modificada y transmitida de persona a persona" (García, 2014, p. 1). Es más, los memes se han vinculado a estrategias que motivan la participación ciudadana en la política con mensajes cortos y sencillos de acuerdo al tipo de público y canal al que se dirige (Gutiérrez, 2010).

Los políticos han entendido que las nuevas estrategias como los memes son la manera más eficaz de "comprimir un hecho político más complejo en un contenido multimedia breve, poderoso y efectivo que genere una reacción inmediata, ya sea a favor o en contra, pero que a nadie le sea indiferente" (Re, 2014, p.39). Además, la política deja de ser "selectiva" pues con el uso de los memes cualquier persona puede enterarse qué pasó, por qué un candidato es elogiado o ridiculizado.

Los memes constituyen un nuevo género de comunicación política y suelen tener al menos una de estas dos características: son bromas internas y provocan una reacción emocional. En las campañas políticas, los memes son utilizados por partidarios y opositores para transmitir información con lenguaje simple e irónico, con humor en un contenedor breve (Flynn, 2019), potente y eficaz que atrae a las personas (Piñero-Otero \& Martínez-Rolán, 2016). Sin embargo, cuando los actores políticos los emplean como parte de su plan de marketing político digital, deben tomar en cuenta la unidad interna de su partido o agrupación. “Los planes para el desarrollo de estrategias de marketing político, la creación de marcas de candidatos, el desarrollo de productos políticos o la comunicación política pueden fracasar si se ignora la solidez interna" (Mahestu \& Sumbogo, 2020, p. 694).

Kulkarni (2017) indica que el humor y la sátira (impregnada de ironíal se han usado históricamente en forma de comentario político y esto se ha normalizado como comportamiento en diferentes campañas políticas. Ambas variedades de la comicidad, que dan rienda suelta a sentimientos y emociones que producen placer (Freud, 2012), pueden emplear la estética de la cultura popular que, como sensibilidad, obedece a un conjunto de interacciones entre el mundo y el cuerpo que re- flejan "the whole of our sensate life" o "la totalidad de nuestra vida sensible" (Eagleton, 1990, p. 328). En contraste, otros, obviando esta combinación del humor con el alivio y la relevancia cultural, prefieren vincularlo al ámbito del entretenimiento de masas o "sociedad del circo", "carnavalizando los procesos políticos, desarrollando y fortaleciendo el fenómeno que los investigadores occidentales llaman politainment" (Shomova, 2019, p. 159).

\section{Marco metodológico}

Con el objetivo de identificar las características más notables de los memes utilizados en las últimas campañas presidenciales de Perú y Bolivia de la primera década del siglo XXI -y las reacciones que estos instrumentos virtuales han generado en la red social Facebook-, hemos empleado un método mixto con propósitos descriptivos, ya que con ello podemos identificar un conjunto de factores por los que los memes se convierten en estrategias importantes en las campañas políticas (Malhotra, 2008).

Una primera etapa consistió en analizar memes que circularon durante las campañas políticas de los candidatos a las elecciones generales de Perú y Bolivia. Para ello, se construyó una muestra intencionada a partir de los memes producidos, circulados y compartidos en los fanpage de los grupos de redes sociales que cuentan con el mayor número de seguidores e interacción de ambos países (Política en Bolivia, BOLIVIA SOY!!!, Crítica de la Economía Política-Bolivia, Caricaturas Políticas, Política Perú, POLÍTICA DEL PERÚ).

Se analizaron 80 memes haciendo uso de una ficha de análisis basada en las dimensiones de información e interactividad, empleadas para evaluar el fomento de la participación ciudadana en sitios web de De Landtsheer, Krasnoboka y Neuner (1999). A eso, agregamos otras tres dimensiones: mensaje, intencionalidad del mensaje y contenido visual, que son empleadas en los estudios de comunicación política.

De esta forma, presentamos los marcos que definen cada una de estas dimensiones:

Información: representa los datos esenciales del meme para el cual se dividió cada muestra en cinco rangos (datos personales del candidato, datos del 
partido, datos del contrincante, tema de actualidad y tema de campañal.

Interactividad/ viralización: permite evaluar la popularidad y vialidad de los memes (Beskow, Kumar \& Carley, 2020). Para ello, cada muestra se dividió en cinco rangos (número de me gusta, número de compartidos, creación de hashtag, comentarios e impresiones).

Mensaje: analiza el efecto que produce secuencialmente un mensaje, para el cual se dividió en cuatro rangos (atención, interés, deseo y acción) (Gordillo, 2019).

Intencionalidad del mensaje: para este criterio, se consideraron siete rangos: por rechazo del político, notoriedad del político, notoriedad positiva de sus propuestas, notoriedad positiva del partido, rechazo del contrincante, rechazo de sus propuestas del contrincante y rechazo al partido del contrincante (Vega, Gutiérrez \& Torres, 2016).

Contenido visual: este criterio evalúa la estética del meme y permite explorar el nivel de complejidad del diseño. En esta dimensión se analizaron cinco rangos por protagonista del líder político, protago- nismo de los contrincantes, equilibrio entre gráfica y texto, elementos visuales dinámicos, atractivos y combinación armoniosa de colores (Vargas, 2013).

Para efectos de este trabajo, cada una de estas dimensiones fue trabajada por niveles. El procedimiento que se empleó para la obtención de resultados se realizó mediante los totales adquiridos por cada nivel multiplicado por la posición que ocupan, es decir, el total del nivel uno, se multiplica por uno $\left(8^{*} 1\right)$, el total del nivel dos por dos (8*2) y así sucesivamente. Se tomó este criterio porque un meme no necesariamente abarca todos los niveles. Es por ello que, mientras más rasgos de cada nivel se cumplan, más sofisticados e interactivos se convierten estos instrumentos virtuales. En ese sentido, si los memes cumplen con todos los niveles, cada dimensión valdría lo siguiente: Información (10), Interactividad/Viralización (20), mensaje (24), contenido visual (50), e intencionalidad del mensaje (56).

El cálculo general se realizó mediante la suma de los subtotales de las tres dimensiones $(10+20+24+50+56)$ que dan un total de 160 puntos. Tomando en cuenta estos criterios, si un meme adquiere el puntaje total, este sería 100\% efectivo.

Tabla 1: Ficha de análisis.

\begin{tabular}{|c|c|c|c|c|c|c|c|}
\hline Flcha de Análisis & & & & & & & \\
\hline Fecha: & \multicolumn{2}{|c|}{ Nombre del meme: } & & & Pais: & \multirow[b]{2}{*}{ Ponderside } & \multirow[b]{2}{*}{ Totales } \\
\hline 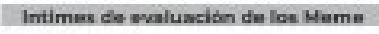 & Valer & Pondurado & Tacalus: & Intimes de evaluacion def los Neme & Waler & & \\
\hline 1. Información & & Pand"1 & 10 & 4. Intenclanallidad del monsaje & & Pand"4 & 56 \\
\hline Datos personales del camididato & Valor $(0+2)$ & & & Rechaso del politico & Valor $[0, a$ ] & & \\
\hline Daseses del partido & Valor (0) & & & Netorieded pesitiva del polikios & velor to \& 24 & & \\
\hline Dastae dol comtrincartes & value $(0.2)$ & & & Notorieded pesitiva de sus propuestas & valor 10.24 & & \\
\hline Tema de actualibsed & Valor $(0,3)$ & & & Matoriedad peaittiva del partido & Valor $10=24$ & & \\
\hline Tama de in campaha & Valor $(0,2)$ & & & Mochass del contrincants & valor 10 a 2 ) & & \\
\hline 2. Interactividad / viralización & & Pond"z & 20 & Rechaes a sus propuestas del conterineants & Valoe $(0, a)$ & & \\
\hline Númora de me guets & Valar $10 \leq 24$ & & & Dechazo al partido del contrincante. & Valor $10=2$ & & \\
\hline Númaro de campartiso & Valor $10=21$ & & & & & & \\
\hline Crosclen do hachesag & Vhlor 10 a 4 & & & 5. Contenido visual & & Pand's: & 50 \\
\hline cempanidas & valor fo a a & & & \multirow{2}{*}{ 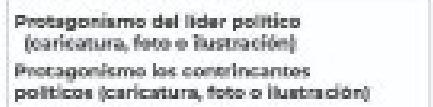 } & valoe $(10.2 \mathrm{z})$ & & \\
\hline 3. Mensaje & & Pond'3 & 24 & & valiee pos a & & \\
\hline Atancilen & $\begin{array}{l}\text { Valor }(0 \cdot 2] \\
\text { valor } 10,2]\end{array}$ & & & Equaliberio entre graria y texto & Valor $p, \pi$ ג & & \\
\hline Deseos & Valoer 10.21 & & & Elementao vibualua dinamicos y atractives & Valox $(0,1)$ & & \\
\hline Accibs & Valor $(0,12]$ & & & Combinacion armoniosa de coliorer & Valor $10=2$ & & \\
\hline \multirow{2}{*}{\multicolumn{3}{|c|}{ Total de la columna }} & 54 & \multirow{2}{*}{\multicolumn{2}{|c|}{ Total de la columna }} & & 106 \\
\hline & & & & & & da la ficha: & 160 \\
\hline
\end{tabular}

Fuente: Elaboración propia. 
La segunda etapa fue la elaboración de una encuesta con el fin de estudiar el impacto de los memes analizados de Perú y de Bolivia. Al respecto, se elaboró un formulario que fue enviado por Facebook Messenger para contactar a los más de 50 mil miembros pertenecientes a los grupos que hemos seleccionado. De todo ese universo, solo atendieron y respondieron a nuestro cuestionario, entre noviembre de 2019 y febrero de 2020, 304 ciudadanos de sexo masculino y femenino (1\%), cuyas edades, recogidas por nuestro instrumento, fluctúan entre 18 a 45 años. El registro y análisis de datos fue trabajado en una base de datos en Excel@

\section{Resultados}

\subsection{Categorías de los memes en las campañas electorales de 2016 y 2019 de ambos países}

El análisis de los memes se organizó en torno a cinco categorías: 1. La reputación del candidato; 2. La realidad política; 3. El discurso político; 4. La identidad cultural, y, 5. La capacidad intelectual del candidato, las cuales se originaron temáticamente de acuerdo a los diversos memes analizados según dimensiones. Al respecto, se observaron varios patrones en común basados en la construcción de la imagen del político (Baeza, 2012; Alonso \& Adell, 2011; Llorens 2008). Hemos considerado la ejemplificación de un meme por país a fin contextualizar el análisis realizado en la investigación.

\subsubsection{Reputación del candidato}

En esta categoría se encuentran los memes enfocados en la vida personal y experiencia laboral del candidato. Muchas de las piezas gráficas tuvieron un enfoque negativo y fueron utilizadas por los contrincantes para desprestigiar al político. En Perú, resaltaron el alcoholismo de Alejandro Toledo; sobre el candidato Alan García, se enfocaron en las denuncias públicas, acciones negativas realizadas durante su periodo de gobierno; en la candidata Keiko Fujimori, en su falta de experiencia laboral. En Bolivia, se enfocaron en el tiempo que Evo Morales estaba en el poder, resaltando que las elecciones no tenían sentido porque el candidato
Imagen 1: Sátira a la reelección de Evo Morales.

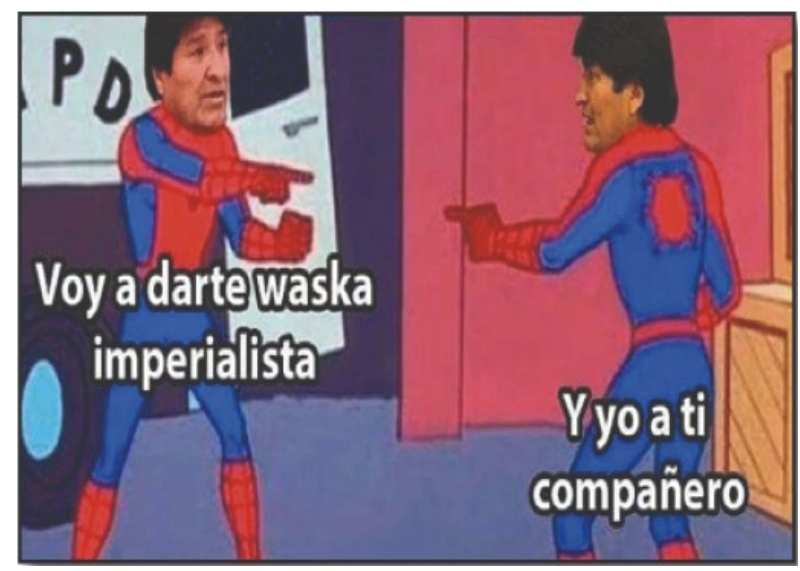

Fuente: Memes de Evo Morales y los masistas. (2019).

Imagen 2: Toledo en el debate presidencial.

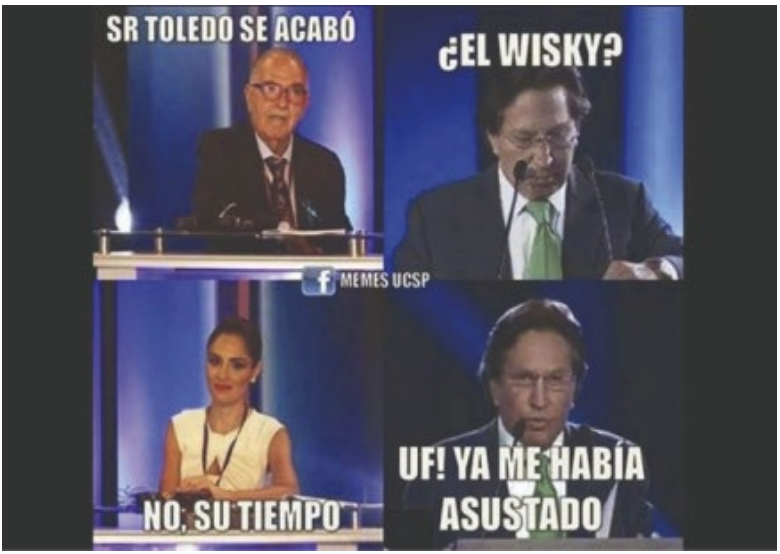

Fuente: Memes UCSP. (2016).

En el primer meme, utilizado en la campaña electoral de Bolivia, se hace alusión al personaje de ficción Spiderman. Evo Morales, vestido como hombre araña, le advierte a su otro yo, que es él quien también le dará "waska" (látigo). Este mensaje nace a raíz de la declaración de Morales contra la derecha boliviana. En cuanto a la interactividad es intermedia, está centrada en el protagonista, el mensaje es directo (al ser informativol y de acción porque establece un hecho. La intencionalidad del mensaje es criticar de manera cómica a Evo, ya que ha representado a Bolivia durante varios gobiernos sucesivos. El meme crea la situación y la acopla a una serie animada. En el aspecto visual, estéticamente, cumple con su cometido armonioso: el color y el texto se corresponden sin problemas. Sin embargo, la información que nos brinda, si bien es básica, solo se entendería en el contexto latinoamericano. 
En el segundo meme, utilizado en la campaña electoral de Perú, la finalidad es hacer burla de los problemas con el alcohol del expresidente Alejandro Toledo. En el ítem de información, se brinda el nombre y el rostro del protagonista. En la dimensión de interactividad/viralización tuvo mucha acogida por diversos factores que van desde la comicidad hasta el uso correcto del diálogo. Este meme alcanzó 6.133 likes, 250 comentarios y 4.400 compartidos. En cuanto al mensaje, el punto de atención, interés y acción es Toledo como una forma de protesta por su comportamiento incorrecto, pero de forma humorística. Esto está relacionado con la intencionalidad del mensaje: el protagonista resulta perjudicado resaltando el arquetipo que representa el expresidente. En cuanto al contenido visual, el protagonista es caricaturizado y puesto en ridículo de forma sutil. La combinación de la gráfica y el texto logran compactarse para lograr la inteligibilidad del mensaje.

\subsubsection{Realidad política}

Durante estas campañas electorales, algunos memes se enfocaron en la evaluación de la política que tienen Bolivia y Perú. Hicieron hincapié en el populismo, en la facilidad de convertirse en un político y en cómo se pueden manipular los procesos. En el ejemplo expuesto por cada país, se puede visualizar esta categoría con más detalle.

Imagen 3: Candidatos elecciones Bolivia. Bolivianadas.com. (2019]

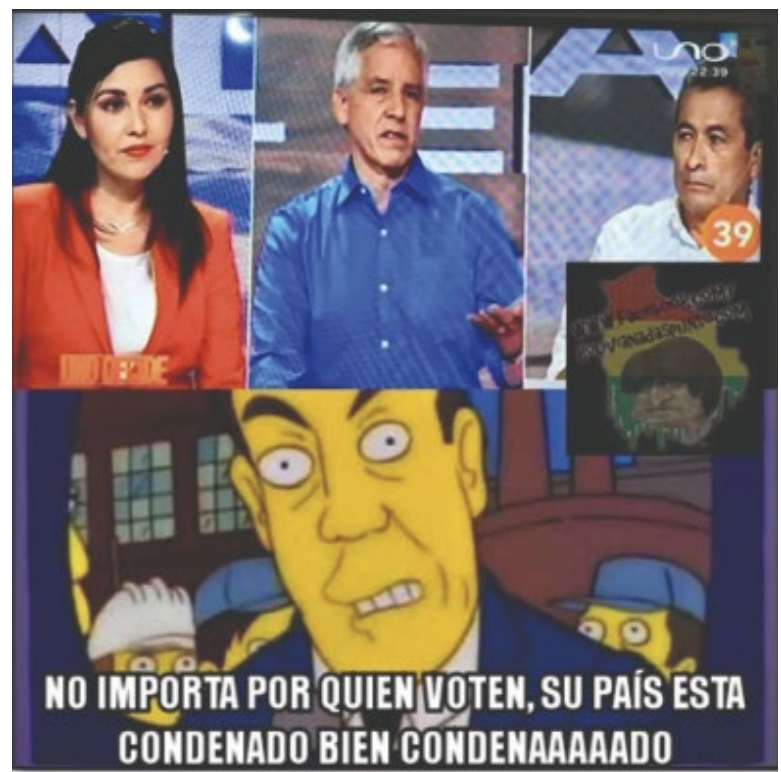

Fuente: Memes UCSP. (2016)
Imagen 4: César Acuña y Julio Guzmán enfrentando la tacha presidencial.

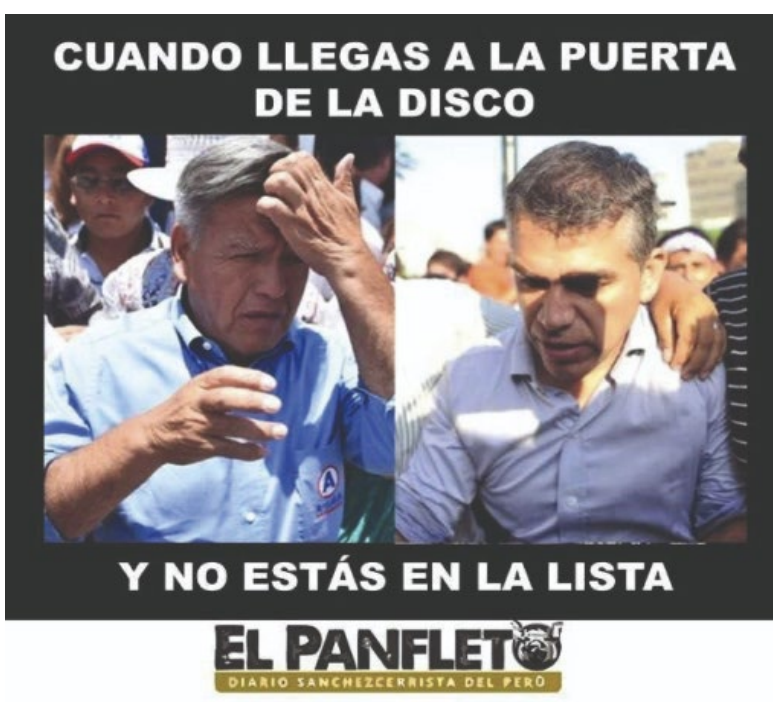

Fuente: El Panfleto, Perú. (2016).

En la imagen 3, en cuanto a la interactividad/viralización, este meme obtuvo 10.000 likes, 664 comentarios, 3.900 compartidos e impresiones. En cuanto al mensaje, nos dice que los políticos no deberían representar a la República. Este meme puede ser considerado como pesimista para algunos. La intencionalidad del mensaje es perjudicar la imagen de los candidatos. En lo que respecta al contenido visual, resaltan los protagonistas y contrincantes a través de fotografías. Pese a no tener nombres, el texto ayuda, pero no soluciona el problema de información. Hay presencia de un logo que cubre parcialmente el meme.

En la imagen 4, la información textual, a diferencia de otros memes, está dentro de sus propios marcos. El nivel de interactividad que tuvo fue alto $(11.000$ likes, 689 comentarios y 3.700 compartidos); los comentarios, en general, fueron positivos, algunos defendieron a sus candidatos mientras que otros se dedicaron a opinar sobre la realidad política y el tipo de candidatos que tiene el país. En cuanto al mensaje, éste está centrado en figuras que seguramente fueron expulsadas de la contienda electoral, como fue el caso de César Acuña de Alianza para el Progreso y Julio Guzmán del Partido Morado. El texto logra ser preciso y comprensible en el contexto peruano. La intención del mensaje es hacer mofa de la situación de los candidatos. Ambos protagonistas son afectados, pero no son aliados políticos. 


\subsubsection{Discurso político}

Los memes se enfocaron principalmente en el discurso, desde el punto de vista de la comunicación lingüística y la comunicación no verbal. En el caso del candidato de Bolivia, Evo Morales, se resaltan acciones como las de coger un pañuelo para limpiarse las lágrimas al momento de dirigirse a la población. Eso muy bien puede reflejar el lado humano, pero al mismo tiempo lo hace objeto de diferentes memes, apelando a un sentido de debilidad. En la Imagen 5 se muestra a un político del oficialismo lálvaro García, del equipo de Evo Mora(es), que dio unas declaraciones que fueron duramente criticadas: "si había un Evo hace 100 años, no perdíamos el mar". El punto de interactividad/ viralización alcanzó 8.000 likes, 202 comentarios, 400 compartidos e impresiones. La intencionalidad del mensaje está enfocada en ridiculizar al político quien tuvo un incidente con un cálculo matemático. En el aspecto visual no existe armonía en el diseño: el texto logra ser legible, pero el color no es compatible.

En el caso de Perú, el meme recogido en la Imagen 6 apela a la edad y la experiencia del candidato Pedro Pablo Kuczynski (PPK, Peruanos Por el Kambio), en un momento en que este trolea a su otro par (Keiko Fujimori, de Fuerza Popular). La información que nos brinda no está completa ya que no se visualiza la fotografía de la contrincante. La interactividad del meme fue alta debido a la composición y la referencia animada. Alcanzó 10.200 likes, 1.300 comentarios y 1.500 compartidos. En cuanto al mensaje, centra la atención en los dos candidatos. El interés es fuerte porque PPK es discutido por su amplia experiencia (lobbysta) y, en el caso de la candidata Fujimori, por su falta de práctica laboral. La intencionalidad del mensaje fue favorecer a la propuesta y la imagen del protagonista (PPK). En el aspecto visual, se usan dos estilos gráficos, uno real y el otro animado. La composición de imagen y texto es notable. La imagen se muestra como un buen apoyo.

\subsubsection{Identidad cultural}

Esta categoría se enfoca en los valores, tradiciones y en el comportamiento de los candidatos. Como vemos en el ejemplo, en los memes no se desaprovechan algunas oportunidades para ridiculizar
Imagen 5: Sátira a García, un político boliviano.

\section{El matemático: $2018-100=1879$}

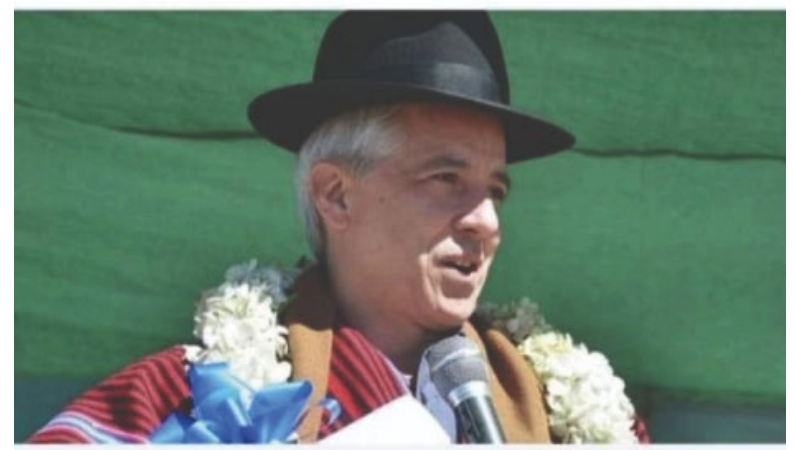

\section{ERBOL.COM.BO}

\section{García: Si había un Evo hace 100 años, no perdíamos el mar}

Fuente: Bolivia memes. (2018).

Imagen 6: Las declaraciones de Pedro Pablo Kuczynski tras el debate.

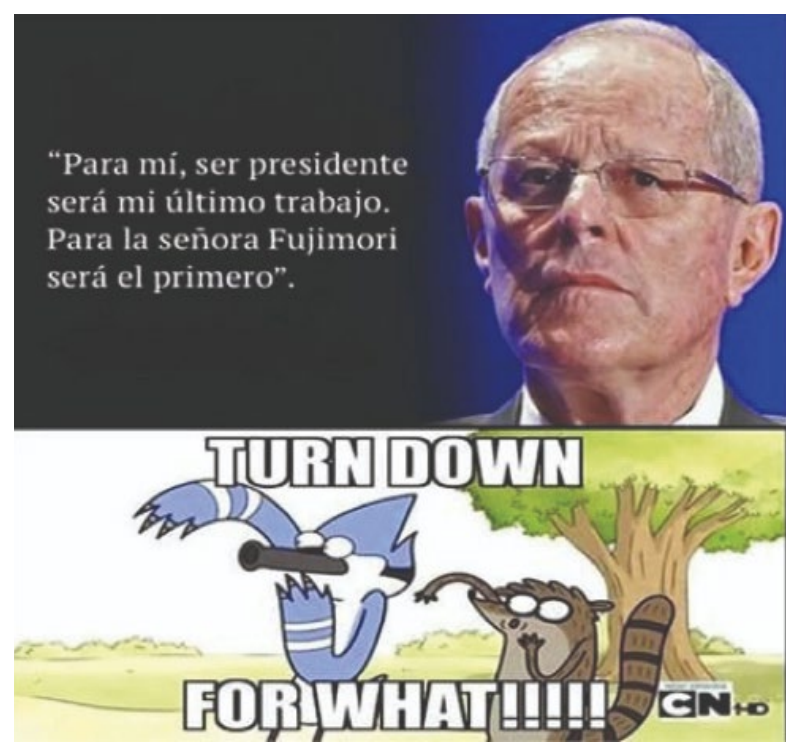

Fuente: El Panfleto, Perú. (2016).

En la Imagen 7, el meme tuvo la finalidad de ridiculizar por la vía del estereotipo al candidato de origen asiático Chi Hyun Chung. A pesar de obtener un porcentaje de votos importante, no pudo ganar las elecciones por no ser ciudadano boliviano. La información que brinda este meme es básica, no muestra nombres, no toca un tema político, ni menciona a algún contrincante. La interactividad/ viralización de este meme tiene un nivel intermedio (4.200 likes, 530 comentarios y 300 comparti- 
dos). En cuanto al mensaje, el punto de atención, interés y acción está en el candidato. Este meme es una forma de broma racial que se asocia a estereotipos coreanos de k-pop. La intencionalidad del mensaje es ridiculizar al candidato con sorna. En el contenido visual cumple los cánones de diagramación y diseño: el color y la superposición de imágenes logran el objetivo, pero en el texto informativo su falencia es más evidente.

Imagen 7: Una sátira a Chi Hyun Chung. It 's DaniCrist. (2019).

\section{NO TODO ESTA PERDIDO AUN FALTA LA PRUEBA DEL TRAUE DE BAÑO}

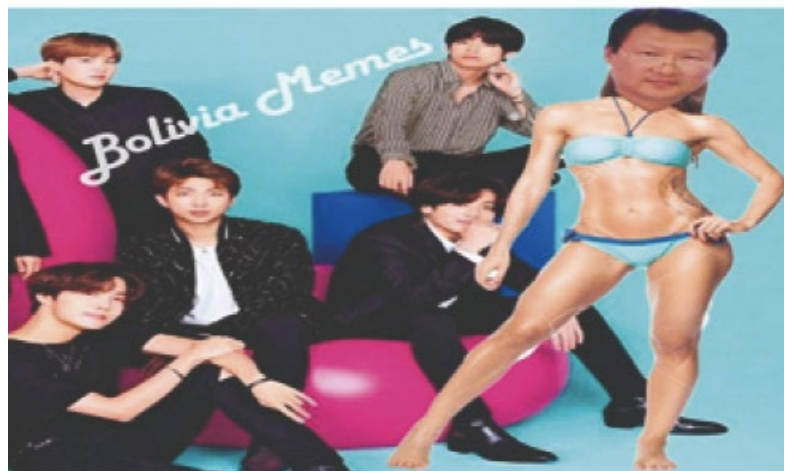

Fuente: Bolivia memes. (2018).

La Imagen 8 se burla del candidato Alfredo Barnechea, quien era un candidato con buena aceptación a nivel de encuestas, pero que terminó marginado de esta medición por algunas malas decisiones tomadas en su campaña en las provincias. Fue el caso de no aceptar comer un chicharrón en un mercado. Por esto lo catalogaron como el candidato de los ricos, con un hombre que no se identifica con el pueblo.

Imagen 8: Barnechea y el incidente del chicharrón.

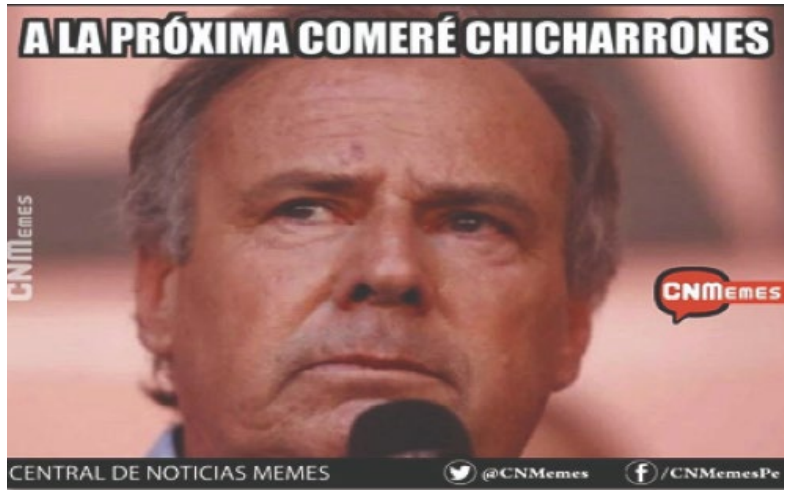

Fuente: CNMemes. (2016).
En cuanto a la información que nos brinda este meme es limitada: no da nombres, ni agrupaciones políticas. Solo en el contexto peruano es posible entender esta representación. Sobre su interactividad cuenta con 400 likes, 20 comentarios y 45 compartidos. Respecto al mensaje este es simple y capta la atención de la audiencia. La intencionalidad del mensaje es, sin duda, perjudicar la imagen del candidato, ya que se hace mofa de su caída en las encuestas. En el aspecto visual el texto es corto y la fotografía por sí sola transmite la idea. El poco uso de efectos visuales logra que el meme pueda presentarse solo, sin ninguna explicación.

\subsubsection{Capacidad intelectual del candidato}

Diversos memes analizados apelaron al coeficiente intelectual de los candidatos.

Imagen 9: César Acuña y el incidente del plagio.

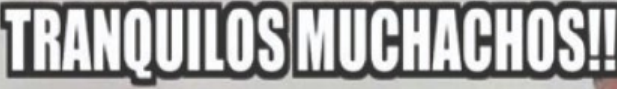

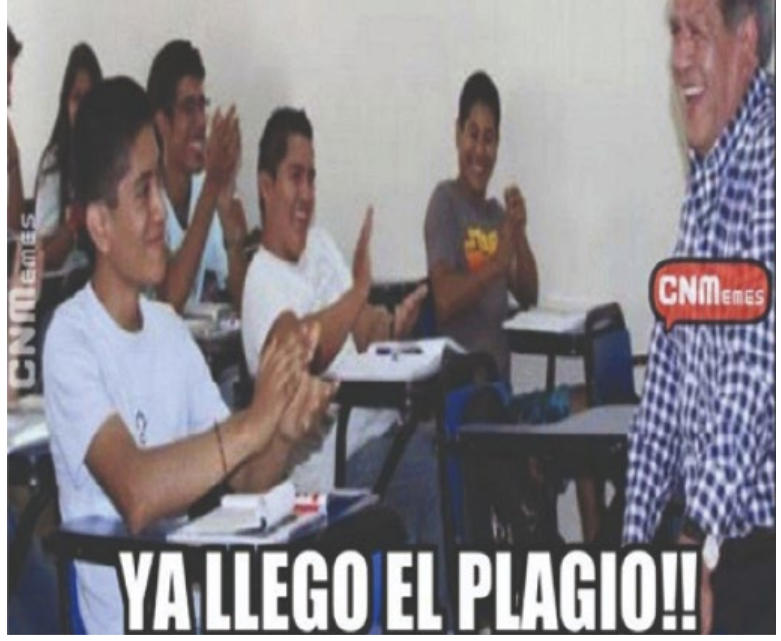

Fuente: CNMemes. (2016)

En la Imagen 9, la información que brinda es clara. El candidato presidencial César Acuña es punto de burla por plagio académico, poniendo en evidencia su capacidad intelectual en cuanto a la interactividad/viralización (300 likes, 30 comentarios y 50 compartidos). Pese a ser un meme controversial y de mofa, no consiguió mucha interacción. En cuanto al mensaje, el foco de interés es el protagonista, el mensaje es directo (al ser informativo), de acción porque establece un hecho. En el aspec- 
to visual, el protagonista es caricaturizado con el personaje del Chavo del 8 (Ñoño). En la Imagen 10, el meme tiene como fin ridiculizar a Evo Morales frente a Nicolás Maduro. A Evo se le compara con un burro, insinuando su poca supuesta capacidad intelectual. El ítem de información no tiene mucho puntaje porque no se da información puntual del partido político, ni del contrincante. En cuanto a la interacción y viralización de este meme resultó efectiva, ya que se alcanzaron más de 300 likes y 80 compartidos. En el mensaje el punto de atención, interés y acción están enfocados en Maduro y Evo Morales, pues se asume que tienen una alianza ideológica. Ambos se apoyan para lograr objetivos políticos. La intención del mensaje busca perjudicar con sarcasmo la imagen de Evo. En el aspecto visual hay un equilibrio entre el texto y el color de la fotografía, la información es precisa y se mantienen las formas estéticas. Tiene un diálogo cómico.

\subsection{Resultados generales de las cinco dimensiones}

Tomando en cuenta la metodología de conteo expuesta en el punto 3 , se visualiza que los memes de Perú son más completos que los de sus pares bolivianos porque cuentan con los siguientes datos: candidato, partido, contrincante, tema
Imagen 10: Nicolás Maduro defendiendo a Evo Morales.
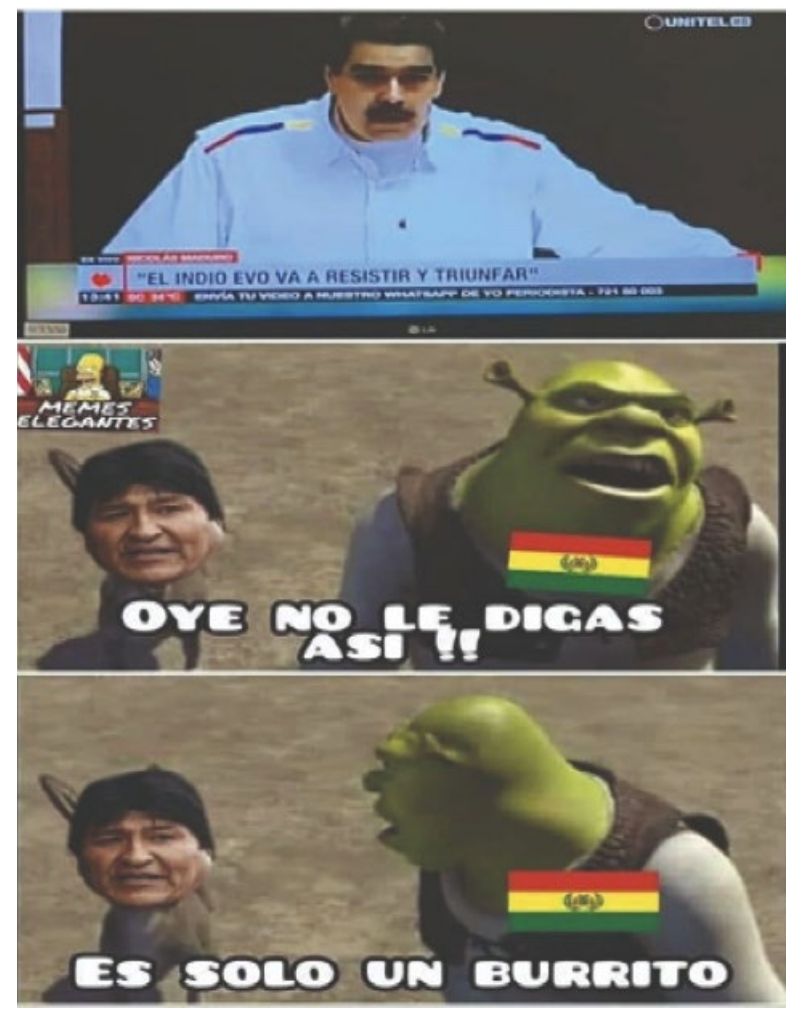

Fuente: Bolivia Memes (2019).

de actualidad y tema de la campaña. Asimismo, el nivel de interactividad es alto en comparación de los memes usados en Bolivia, pues estos memes fueron más compartidos, tienen más likes y comentarios. Igualmente, los memes en Perú du-

Imagen 10: Nicolás Maduro defendiendo a Evo Morales.

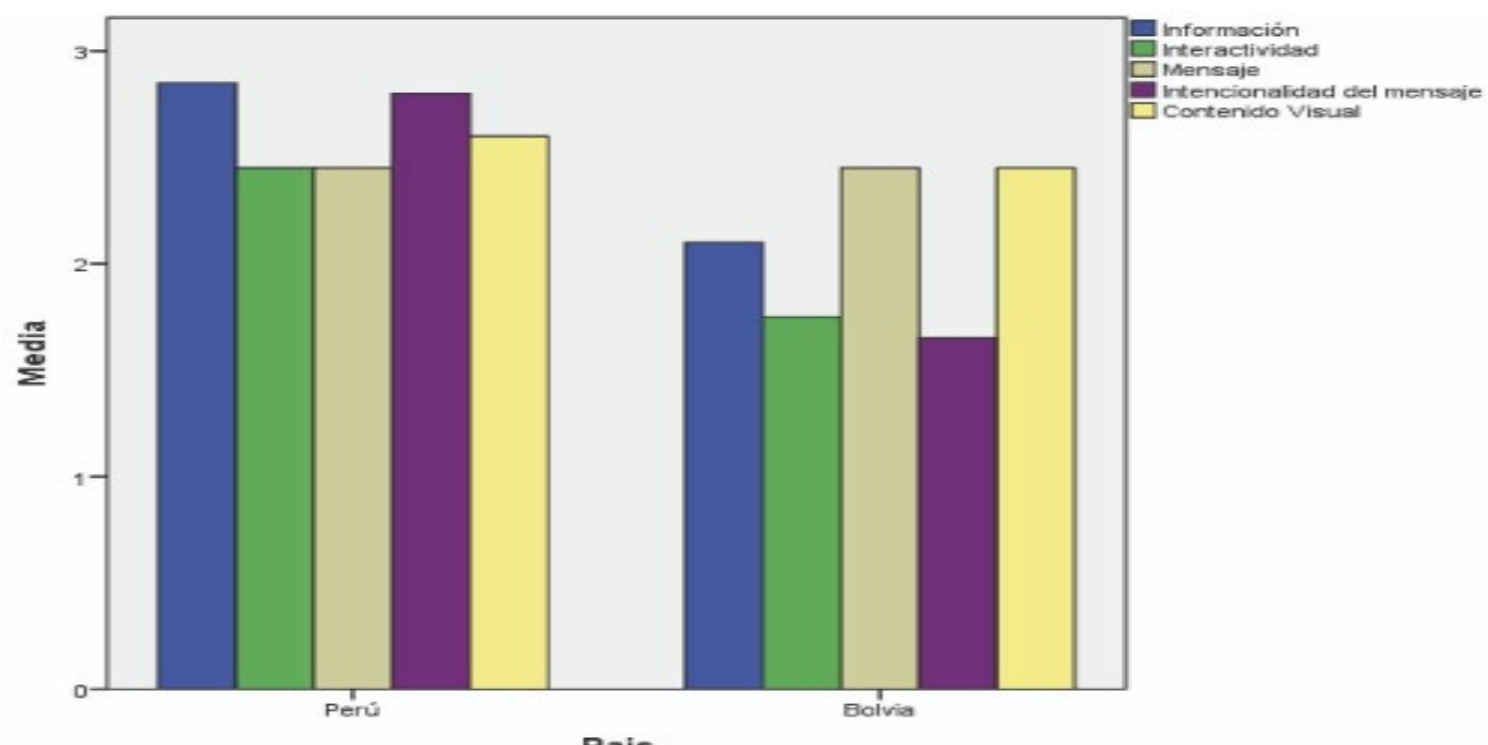

Fuente: Elaboración propia. 
rante la contienda electoral tuvieron un nivel de intencionalidad del mensaje alto, es decir, que los memes y sus mensajes se dirigían ya sea con rechazo del político, notoriedad positiva del político, notoriedad positiva de sus propuestas, notoriedad positiva del partido, rechazo del contrincante, rechazo a sus propuestas del contrincante y rechazo al partido del contrincante. Los memes utilizados en las elecciones presidenciales en Bolivia están más enfocados en el mensaje y cumplen con los criterios de atención, interés, deseo y acción. En cuanto al contenido visual, si bien es cierto los memes de Bolivia no presentan un nivel tan bajo, igualmente terminan superados por lo que vemos en Perú, pues sus memes tienen como protagonista al líder político (caricatura, foto o ilustración) o a los contrincantes políticos (caricatura, foto o ilustración). Por otro lado, se visualiza que en ambas campañas políticas hay un equilibrio entre gráfica y texto. De la misma manera, los elementos visuales son dinámicos y atractivos.

\subsection{Reacciones frente a los memes utilizados en las campañas electorales de Perú y de Bolivia}

Para analizar las reacciones frente a los memes utilizados en las campañas electorales de Perú y
Bolivia fueron recogidas, a través de un cuestionario, las opiniones de 304 ciudadanos de sexo masculino y femenino, cuyas edades fluctúan entre 18 a 45 años en los grupos con más seguidores e interacción de Facebook.

En la tabla 2 se observa que los bolivianos, en todos los segmentos de edad por nivel educativo, con excepción del de formación superior 136-45 años), consideran que los memes sí son importantes. Principalmente, los ciudadanos más jóvenes y con formación básica son los más inclinados a creerlo así. En el caso del Perú, hay un mayor porcentaje de escépticos, con excepción del rango y nivel de 36-45 años (contrario a lo que sucede en Bolivial porque el total de encuestados tiende a aceptar los memes como una importante estrategia de comunicación para hacer campaña.

En el caso de Bolivia, el segmento de 46-55 años, en nivel de educación básico, considera que los memes que se usaron sí fueron ofensivos para el partido político de su preferencia $(66.7 \%)$; mientras que todo lo contrario ocurre con el segmento de 26-35 y de nivel básico, quienes junto con los de nivel técnico, piensan que estos recursos tal vez lo hayan sido (25\%) o no lo han sido (50\%). En Perú, el total de los encuestados de ese mismo rango de edad, pero con otra formación diferente a la básica, técnica y superior, expresaron que los memes que se emplearon en las redes sociales

Tabla 2: Importancia de los memes por rango de edad y nivel educativo.

\begin{tabular}{|c|c|c|c|c|}
\hline Edad & Respuestas & Nivel educativo & Bolivia & Perú \\
\hline \multirow{3}{*}{$18-25$} & sí & $\begin{array}{l}\text { Básica } \\
\text { Técnica } \\
\text { Superior }\end{array}$ & $\begin{array}{c}40 \% \\
20 \% \\
0 \%\end{array}$ & $\begin{array}{l}20 \% \\
0 \% \\
0 \%\end{array}$ \\
\hline & NO & $\begin{array}{l}\text { Básica } \\
\text { Superior }\end{array}$ & $\begin{array}{c}33,3 \% \\
0 \%\end{array}$ & $\begin{array}{l}33,3 \% \\
33,3 \%\end{array}$ \\
\hline & Tal vez & Básica & $0 \%$ & $20 \%$ \\
\hline \multirow{2}{*}{$26-35$} & sí & Técnico & $50 \%$ & $0 \%$ \\
\hline & NO & $\begin{array}{l}\text { Básica } \\
\text { Otros }\end{array}$ & $\begin{array}{l}50 \% \\
0 \%\end{array}$ & $\begin{array}{c}0 \% \\
100 \%\end{array}$ \\
\hline $36-45$ & sí & Superior & $0 \%$ & $100 \%$ \\
\hline \multirow{2}{*}{$46-55$} & sí & Superior & $50 \%$ & $0 \%$ \\
\hline & NO & Básica & $50 \%$ & $100 \%$ \\
\hline
\end{tabular}


Tabla 3: Uso de memes ofensivos para atacar al partido político de preferencia en las últimas elecciones precidenciales.

\begin{tabular}{|c|c|c|c|c|}
\hline Edad & Respuestas & Nivel educativo & Bolivia & Perú \\
\hline \multirow{3}{*}{$18-25$} & sí & $\begin{array}{l}\text { Básica } \\
\text { Técnico } \\
\text { Superior }\end{array}$ & $\begin{array}{l}40 \% \\
20 \% \\
20 \%\end{array}$ & $\begin{array}{l}20 \% \\
0 \% \\
0 \%\end{array}$ \\
\hline & NO & $\begin{array}{l}\text { Básica } \\
\text { Superior }\end{array}$ & $\begin{array}{c}33,3 \% \\
0 \%\end{array}$ & $\begin{array}{l}33,3 \% \\
33,3 \%\end{array}$ \\
\hline & Tal vez & Básica & $0 \%$ & $20 \%$ \\
\hline \multirow{3}{*}{$26-35$} & sí & Técnico & $25 \%$ & $0 \%$ \\
\hline & NO & $\begin{array}{l}\text { Básica } \\
\text { Otros }\end{array}$ & $\begin{array}{c}50 \% \\
0 \%\end{array}$ & $\begin{array}{c}0 \% \\
100 \%\end{array}$ \\
\hline & Tal vez & Técnico & $25 \%$ & $0 \%$ \\
\hline $36-45$ & sí & Superior & $0 \%$ & $100 \%$ \\
\hline \multirow{2}{*}{$46-55$} & sí & $\begin{array}{l}\text { Básico } \\
\text { Superior }\end{array}$ & $\begin{array}{l}66,7 \% \\
33,3 \%\end{array}$ & $\begin{array}{l}0 \% \\
0 \%\end{array}$ \\
\hline & Tal vez & Básica & $0 \%$ & $100 \%$ \\
\hline
\end{tabular}

Fuente: Elaboración propia (2020).

no buscaban dañar la imagen del candidato de su preferencia. En cambio, los ciudadanos pertenecientes al segmento 36-45 años y de nivel superior expresaron por unanimidad todo lo contrario.
En la tabla 4, el 33.3\% de los encuestados de Perú y Bolivia, en el rango de 18 a 25 años, con nivel superior, opinan que cuando no están de acuerdo con el contenido de un meme lo reportan. En su to-

Tabla 4: Reacciones cuando no están de acuerdo con un meme político.

\begin{tabular}{|c|c|c|c|c|}
\hline Edad & Respuestas & Nivel educativo & Bolivia & Perú \\
\hline \multirow{3}{*}{$18-25$} & Comento y comparto & Técnica & $20 \%$ & $0 \%$ \\
\hline & Lo reporto & $\begin{array}{l}\text { Básica } \\
\text { Técnica } \\
\text { Superior }\end{array}$ & $\begin{array}{c}0 \% \\
0 \% \\
33,3 \%\end{array}$ & $\begin{array}{c}33,3 \% \\
0 \% \\
33,3 \%\end{array}$ \\
\hline & Me burlo & Básico & $40 \%$ & $33,3 \%$ \\
\hline \multirow{2}{*}{$26-35$} & Comento y comparto & $\begin{array}{l}\text { Básico } \\
\text { Técnico }\end{array}$ & $\begin{array}{l}50 \% \\
25 \%\end{array}$ & $\begin{array}{l}0 \% \\
0 \%\end{array}$ \\
\hline & Soy muy indeferente & $\begin{array}{l}\text { Otros } \\
\text { Técnico }\end{array}$ & $\begin{array}{c}0 \% \\
25 \%\end{array}$ & $\begin{array}{c}100 \% \\
0 \%\end{array}$ \\
\hline $36-45$ & Lo reporto & Superior & $0 \%$ & $100 \%$ \\
\hline \multirow{2}{*}{$46-55$} & Comento y comparto & $\begin{array}{l}\text { Básica } \\
\text { Superior }\end{array}$ & $\begin{array}{l}50 \% \\
0 \%\end{array}$ & $\begin{array}{c}0 \% \\
50 \%\end{array}$ \\
\hline & Soy muy indeferente & $\begin{array}{l}\text { Básica } \\
\text { Superior }\end{array}$ & $\begin{array}{c}0 \% \\
50 \%\end{array}$ & $\begin{array}{l}50 \% \\
0 \%\end{array}$ \\
\hline
\end{tabular}


Tabla 5: Postura cuando otras personas utilizan memes que atacan u ofenden al candidato/ partido de su preferencia.

\begin{tabular}{|c|c|c|c|c|}
\hline Edad & Respuestas & Nivel educativo & Bolivia & Perú \\
\hline \multirow{3}{*}{$18-25$} & $\begin{array}{l}\text { Insulto a los } \\
\text { detractores }\end{array}$ & Básico & $50 \%$ & $25 \%$ \\
\hline & $\begin{array}{l}\text { Respondo con } \\
\text { otro meme }\end{array}$ & $\begin{array}{l}\text { Técnico } \\
\text { Básico }\end{array}$ & $\begin{array}{c}0 \% \\
33,3 \%\end{array}$ & $\begin{array}{l}0 \% \\
0 \%\end{array}$ \\
\hline & $\begin{array}{l}\text { Respondo con } \\
\text { un argumento }\end{array}$ & $\begin{array}{l}\text { Superior } \\
\text { Técnico }\end{array}$ & $\begin{array}{c}0 \% \\
20 \%\end{array}$ & $\begin{array}{l}50 \% \\
0 \%\end{array}$ \\
\hline \multirow[t]{2}{*}{$26-35$} & $\begin{array}{l}\text { Respondo con } \\
\text { otro meme }\end{array}$ & $\begin{array}{l}\text { Básico } \\
\text { Técnico }\end{array}$ & $\begin{array}{l}50 \% \\
50 \%\end{array}$ & $\begin{array}{l}0 \% \\
0 \%\end{array}$ \\
\hline & Otros & Otros & $0 \%$ & $100 \%$ \\
\hline $36-45$ & $\begin{array}{l}\text { Respondo con } \\
\text { un argumento }\end{array}$ & Superior & $0 \%$ & $100 \%$ \\
\hline \multirow{2}{*}{$46-55$} & Lo reporto & Superior & $100 \%$ & $100 \%$ \\
\hline & Otros & Básico & $0 \%$ & $0 \%$ \\
\hline
\end{tabular}

Fuente: Elaboración propia (2020).

talidad, este criterio es compartido por el rango de 36 a 45 años, con educación superior, en Perú. La indiferencia hacia este tipo de estrategias se hace notar más en ambos países, sobre todo en los segmentos de 26 a 35 y 56 a 55 años.

En el grupo de 18 a 25 años, el $50 \%$ de bolivianos junto con el $25 \%$ de peruanos de nivel educativo básico reconocieron que insultan a los detractores del candidato/partido de su preferencia. En Bolivia, los del rango de 26-35 años, de nivel básico y técnico, prefieren responder usando otro meme. En Perú, es en el grupo de 36 a 45 años, de nivel superior, donde se inclinan más por el uso de argumentos que defiendan a su candidato/partido de su preferencia. En ambos países, los del rango de 46-55 años, de nivel educativo superior, afirman que estarían en condiciones de reportar cualquier meme que consideren ofensivo a los objetos de sus preferencias electorales.

\section{Discusión y conclusiones}

Según Tenove (2019), los memes funcionan políticamente si son ampliamente compartidos, si ayudan a cultivar un sentido de pertenencia a un "grupo interno" y si hacen una declaración normativa convincente sobre una figura pública o un tema político. Asimismo, si pueden comunicar rápidamente la postura del creador sobre el tema. En una red social como Facebook, cuanto más fuerte sea la respuesta emocional provocada por un post, mayor será la intención de difundirlo.

Sin embargo, como ha ocurrido en países como el Reino Unido, cuando se ha examinado el papel de los memes en las campañas políticas de elecciones generales 2017, las bromas virales si bien pueden ser una forma de participación política que compromete a los ciudadanos, sobre todo a los electores más jóvenes y no sirven necesariamente para aumentar el conocimiento político de una situación (Mcloughlin \& Southern, 2021). En consecuencia, es muy probable que, a partir de los datos aquí expuestos, muchos usuarios peruanos y bolivianos de Facebook hayan visto y compartido contenidos políticos sin haber optado finalmente por ellos.

Lo que sí es posible afirmar es que tomando como base los datos del Latinobarómetro, en los países andinos, como en el resto de la región, existe una ciudadanía insatisfecha, menos tolerante con su clase política y orientada a deslegitimar el sistema político. Debido a ello, han surgido movimientos sociales creados desde las redes sociales digitales que, finalmente, se trasladan a las calles para 
exigir la salida de toda la clase política, acusada de corrupta (Villanueva, 2021).

La relevancia del estudio viene dada por el hecho de que, a diferencia de los investigadores extranjeros que interpretan activamente el papel de la memética en los procesos electorales, el potencial político del meme de Internet ha sido escasamente estudiado en Perú y Bolivia.

Las categorías de los memes que advertimos tanto en la campaña de Perú (2016) como en la de Bolivia (2019) se centran en: 1) La reputación del candidato, donde se resalta el prestigio o desprestigio de los aspirantes a la presidencia, ya sea para favorecerlos o perjudicarlos; 2) La realidad política de acuerdo al contexto de cada país, en este caso se destaca más la calidad política tanto desde el punto de vista de los políticos, los partidos políticos y las instituciones; 3) El discurso, que rescata las falencias de los mensajes de los candidatos, pero donde también se resaltan los discursos positivos para posicionarse; 4) La identidad cultural, donde se hace mofa en las facciones, descendencia de los candidatos, así como el nivel de identificación del candidato con la cultura del país, y; 5) La capacidad intelectual, que es uno de los aspectos más usados en estas dos campañas políticas, pues se hace mucho hincapié en la calidad educativa o la experiencia laboral de los candidatos.

Asimismo, estas categorías tienen relación en los resultados obtenidos en las dimensiones mejor usadas en ambas campañas. Por ejemplo, la dimensión de información en la mayoría de los memes analizados brinda datos personales del candidato, del partido, del contrincante; además de tocar temas de actualidad y de campaña. Otra de las dimensiones es la intencionalidad del mensaje, que se enfoca en resaltar las cualidades negativas de los candidatos o partidos. Dado que los ataques son frecuentes, se hace uso de la estrategia de los memes para resaltar aspectos positivos 0 negativos como el rechazo del político, notoriedad positiva del político, notoriedad positiva de sus propuestas, notoriedad positiva del partido, rechazo del contrincante, rechazo a sus propuestas del contrincante y rechazo al partido del contrincante. Estas categorías se han visto reflejadas en Bolivia, resaltando el tiempo que Evo Morales se mantenía como gobernante de su país, sus rasgos indígenas y su forma de pensar, por ejemplo. En Perú, en tan- to, se enfocaron en los casos de corrupción de los candidatos, así como en la condición de adulto mayor de Pedro Pablo Kuczynski, quien fue uno de los principales candidatos de ese proceso. Este tipo de intencionalidad tiene relación con lo investigado por Schreckinger (2018), quien reveló cómo se hicieron memes para mofarse de Hillary Clinton, entonces candidata del partido Demócrata en EE.UU. en las elecciones presidenciales de 2016.

De acuerdo a la encuesta aplicada en Perú y Bolivia, se destaca que en ambos países existe una tendencia a creer que los memes han sido importantes en las últimas elecciones presidenciales. Sin embargo, en Bolivia se visibiliza con más énfasis, en los segmentos de educación básica de 18 a 25 años (40\%) y de 26 a 36 años (50\%), así como los de nivel superior universitaria de 46 a 55 (50\%). Asimismo, en Bolivia, el segmento más joven y con menor nivel educativo de la lista opinó que se han utilizado memes para atacar al partido de su preferencia en las últimas elecciones. Se asume, como ocurrió en las presidenciales nigerianas de 2015 , que estas representaciones negativas sirvieron para depreciar los valores electorales de los oponentes y aumentar indirectamente las posibilidades electorales de sus candidatos (Tella, 2018).

Hay autores que sostienen que la combinación de diálogo y conflicto son dos funciones principales que contiene el meme político y puede constituirse en un elemento clave que aumenta la popularidad de un meme y que lo hace viral (Lukianova, Shteynman \& Fell, 2019). En nuestro caso de estudio, la viralidad es producto de ciudadanos muy reactivos a publicaciones negativas llenas de emociones. A pesar que, en gran medida, los memes desplegados sobre los candidatos presidenciales puedan servir en gran medida a fines subversivos y a fin de restar valor electoral a los objetivos de un actor específico, puede también, en cuanto a la función de refuerzo del humor, plantear cuestiones sociopolíticas serias para expresar preocupaciones y deseos ciudadanos en un flujo constante de comunicación ascendente (Adegoju \& Oyebode, 2015).

De todos los segmentos estudiados, son los más jóvenes y de nivel de formación básica los que guardan las reacciones más efusivas frente a los memes en las campañas electorales. En ese sentido, los ciudadanos del grupo de 18 a 25 años, de nivel básico (40\% en Bolivia y $33.3 \%$ en Perú) son 
los que más usan estos dispositivos para burlarse cuando no están de acuerdo. Con ello, podemos coincidir con Shomova (2019) que un rasgo característico de la política de la Web 2.0 es que, en los segmentos más jóvenes, los memes están cambiando cada vez más su naturaleza de entretenimiento inocente a comunicación política susceptible de bromas y desinformación, transformando, posiblemente, "la sociedad del espectáculo" en "la sociedad del circo". En otras palabras, estos nuevos espacios de comunicación política pueden convertir el humor satírico, si seguimos a Freud, en una distracción trivial en el mejor de los casos, en una charlatanería peligrosa de desinformación en el peor de los escenarios (McLeod, 2011) o, más allá de las bromas, en un medio de resistencia a los mensajes mediáticos dominantes (Huntington, 2013).

\section{Referencias}

Adegoju, A., \& Oyebode, 0. (2015). Humour as discursive practice in Nigeria's 2015 presidential election online campaign discourse. Discourse Studies, 17(6), 643-662.

Alonso, C. \& Adell, A. (2011). Marketing Político 2.0. Lo que todo candidato necesita saber para ganar las elecciones. Gestión 2000.

Beskow, D. M., Kumar, S., \& Carley, K. M. (2020). The evolution of political memes: Detecting and characterizing internet memes with multi-modal deep learning. Information Processing \& Management, 57(2), 102170.

Baeza, N. (2012). Cómo se construyó el candidato: Un estudio de caso sobre Imagen Política. (Tesis de licenciatura). Facultad de Humanidades, Universidad Nacional de La Plata.

Bull, L., Holland, O. \& Blackmore, S. (2000). On meme-gene coevolution. Artificial Life, 6 , 227-235.

De Landtsheer, C., Krasnoboka, N., \& Neuner, C. (2001). La facilidad de utilización de los websites de partidos políticos. Estudio de algunos países de Europa del Este y Occidental (1999). Cuadernos de Información y Comunicación (CIC), 6, 107-140. https://revistas.ucm.es/index.php/CIYC/article/view/CIYC0101110107A

Durham, W. (1991). Coevolution: Genes, Culture and Human Diversity. Stanford University Press.

Eagleton, T. (1990). The Ideology of the Aesthetic. Blackwell.

Flynn, K. (5 de junio de 2019). The 2020 meme election: How memes became a mainstream tool in politics. Digiday. https://digiday.com/marketing/meme-election-memesbecame-mainstream-tool-politics/

Freud, S. (2012). El chiste y su relación con lo inconsciente. Alianza.

García, D. (2014). Las imágenes macro y los memes de internet. PAAKAT, 6(4).

Gordillo, M. (2019). Análisis del mensaje publicitario. Questiones publicitarias. 2(24), 9598.

Gutiérrez, A. (2010). Creación multimedia y alfabetización en la era digital. En Aparici,R. (Coord.). Educomunicación más allá del 2.0 (pp. 171-185). Gedisa.

Huntington, H. E. (2013). Subversive memes: Internet memes as a form of visual rhetoric. Selected Papers of Internet Research, (14). http://spir.aoir.org/index.php/spir/article/view/785.

Ibáñez, M. (6 de enero de 2021). En 2020 el uso de redes sociales creció un 50\%. La Razón. 
https://www.la-razon.com/financiero/2021/01/06/en-2020-el-uso-de-redescrecio-un-50/

Ipsos. (2020). Uso de Redes Sociales entre peruanos conectados 2020. https://www. ipsos. com/es-pe/uso-de-redes-sociales-entre-peruanos-conectados-2020 INEI.

Knobel, M., \& Lankshear, C. (2007). Online memes, affinities, and cultural production. $A$ new literacies sampler, 29, 199-227.

Kulkarni, A. (2017). Internet Meme and Political Discourse: A Study on the Impact of Internet Meme as a Tool in Communicating Political Satire. Journal of Content, Community \& Communication, 6(3), 13-17. http://dx.doi.org/10.2139/ssrn.3501366 .

Leal-Toledo, G. (2013). Searching for a foundations of memetics. Trans/Form/Ação, 36(1), 187-210.

Levitsky, S., \& Loxton, J. (2013). Populism and competitive authoritarianism in the Andes. Democratization, 20(1), 107-136.

Llorens, R. (2008). La conciencia poética del lector adolescente. Tabanque, revista pedagógica, (21), 11-24.

Lumsden, C. \& Wilson, E. (1981). Genes, Mind and Culture: The Coevolutionary Process. Harvard University Press.

Lukianova, N., Shteynman, M., \& Fell, E. (2019). Political memes in the 2018 presidential campaigns in Russia: Dialogue and conflict. Empedocles: European Journal for the Philosophy of Communication, 10(1), 71-86. https://doi.org/10.1386/ ejpc.10.1.71_1

Mahestu, G., \& Sumbogo, T. A. (2020, August). Marketing of Identity Politics in Digital World (Netnography Study on Indonesian Presidential Election 2019). In 2020 International Conference on Information Management and Technology (ICIMTech) (pp. 693-698). IEEE.

Malhotra, N. (2008). Investigación de mercados. Un enfoque aplicado. Pearson Educación.

McLeod, K. (2011). On pranks. Communication and Critical/Cultural Studies, 8(1), 97-102.

Mcloughlin, L., \& Southern, R. (2021). By any memes necessary? Small political acts, incidental exposure and memes during the 2017 UK general election. The British Journal of Politics and International Relations, 23(1). https://doi. org/10.1177/1369148120930594

Ong, Y.-S., Lim, M. H., \& Chen, X. (2010). Memetic computation-past, present future. IEEE Computational Intelligence Magazine, 5(2), 24-31. https://doi.org/10.1109/ MCI.2010.936309

Pérez, G., Aguilar, A., \& Guillermo, M. E. (2014). El meme en internet: Usos sociales, reinterpretación y significados, a partir de Harlem Shake. Argumentos, 27(75), 79-100.

Piñeiro-Otero, T. \& Martínez-Rolán, X. (2016). The use of memes in the discourse of political parties on Twitter: analysing the 2015 state of the nation debate. Communication \& Society, 29(1), 145-159. http://dx.doi.org/10.15581/003.29.1.sp.145-160.

Rathore, E. (24 de abril de 2019). Living in the Age of Political Memes. The New York Times. https://www.nytimes.com/2019/04/23/style/india-pakistan-political-memes. html

Re, F.A. (2014). La política transmediática. Trama común, 18(1).

Rushkoff, D. (2010). Program or Be Programmed: Ten Commands for a Digital Age. Soft Skull Press. 
Schreckinger, B. (31 de octubre de 2018). How an internet meme beame a Trummp campaingslogan. Washington. Politico. https://www.politico.com/story/2018/10/31/ trump-jobs-not-mobs-slogan-origin-twitter-reddit-949718

Shah, D. V., Cho, J., Eveland, W. P., \& Kwak, N. (2005). Information and expression in a digital age. Communication research, 32(5), 531-565.

Shomova, S. A. (2019). 2018 Russian Presidential Elections in the Mirror of Memes: New Realities of Political Communications. Polis. Political Studies, 3(3), 157-173.

Tejada, D. O. (2020). Discurso multimodal de resistencia en los memes "No a Keiko" antes de la segunda vuelta de las elecciones presidenciales en Perú (2016). (Tesis de maestría). Faculty of Humanities, Stockholm University.

Tella, A. (2018). Humour generation and multimodal framing of political actor in the 2015 Nigerian presidential election campaign memes. The European Journal of Humour Research, 6(4), 95-117. https://doi.org/10.7592/EJHR2018.6.4.tella

Tenove, C. ( 4 de febrero de 2019). The meme-ification of politics: Politicians \&amp; their 'lit' memes. The Conversation. https://theconversation.com/the-meme-ification-of-politics-politicians-and-their-lit-memes-110017

Vargas, J. (2013). Resultados de la investigación aplicada del análisis de contenido en la comunicación publicitaria gráfica. Revista de la SEECI, (32), 41-72.

Vega, M., Gutiérrez, M., \& Torres, F. (2016). Campañas de comunicación: efectos de la configuración del mensaje en la predisposición a la compra de aceite de oliva ecológico. Revista Española de Estudios Agrosociales y Pesqueros, 244, 69-104.

Villanueva, E. (2021). Rápido, violento y muy cercano: Las movilizaciones de noviembre de 2020 y el futuro de la política digital. Fondo Editorial PUCP.

\section{- Sobre el autor y la autora:}

Carlos Ricardo Gonzales-García es docente investigador (Concytec, Perú) y miembro del Grupo de Investigación MediaLab de la Escuela de Comunicación Social de la Facultad de Letras y Ciencias Humanas de la Universidad Nacional Mayor de San Marcos (UNMSM). Magíster en Investigación de la Comunicación por la UNMSM.

Janeth Villegas Arteaga es docente de la Escuela de Comunicación Social de la Facultad de Letras y Ciencias Humanas de la Universidad Nacional Mayor de San Marcos (UNMSM). Magíster en Estudios Avanzados en Comunicación Política por la Universidad Complutense de Madrid. Magíster en Gestión y Dirección de Recursos Humanos por EUDE Business School.

\section{- ¿Cómo citar?}

Gonzales-García, C., \& Villegas-Arteaga, J. (2021). Memes y reacciones ciudadanas en las campañas electorales de Perú (2016) y Bolivia (2019). Comunicación y Medios, 30(44), 28-43. https://doi.org/10.5354/0719-1529.2021.64609 